\title{
Drug utilization audit of antipsychotics using WHO methodology: recommendations for rational prescribing
}

\author{
Iram Shaifali ${ }^{1}$, Rajib Karmakar ${ }^{1}$, Shalini Chandra ${ }^{1 *}$, Santosh Kumar ${ }^{2}$
}

${ }^{1}$ Department of Pharmacology, ${ }^{2}$ Department of Psychiatry, Rohilkhand Medical College, Bareilly, Uttar Pradesh, India

Received: 09 August 2018 Accepted: 31 August 2018

*Correspondence to:

Dr. Shalini Chandra, Email: pharmapublications@ rediffmail.com

Copyright: (C) the author(s), publisher and licensee Medip Academy. This is an openaccess article distributed under the terms of the Creative Commons Attribution NonCommercial License, which permits unrestricted noncommercial use, distribution, and reproduction in any medium, provided the original work is properly cited.

\begin{abstract}
Background: Utilization pattern of antipsychotics has undergone a major shift as the newly introduced atypical antipsychotics have heralded the market. Hence continuous studies on current prescribing trends are needed to provide most updated, effective and rational treatment of psychoses.

Methods: This cross-sectional prospective study was conducted at Rohilkhand Medical College and Hospital, Bareilly, Uttar Pradesh, India. OPD tickets of the department of psychiatry for the year 2016-2017 were evaluated for a total of 310 cases. These prescriptions were used to determine the drug utilization of antipsychotics and for their appropriateness against the WHO recommended core prescribing indicators
\end{abstract}

Results: A total of 310 patients satisfied the inclusion criteria and a male predominance was seen (male:female $=1.3: 1$ ). The most common psychotic disorder diagnosed was schizophrenia (44\%). Majority of the patients (76\%) received monotherapy and the prescribing trend showed a higher use of atypical antipsychotics $(89 \%)$ over typical ones $(11 \%)$. The most commonly prescribed anti-psychotic drugs were olanzapine (31\%), followed by risperidone $(26 \%)$. On analysing prescriptions according to the WHO core prescribing indicators it was observed that average number of antipsychotics prescribed per prescription was 1.32. $24 \%$ of drugs were prescribed by generic name and $5.2 \%$ were administered via injectable route. Drugs prescribed from National list of Essential Medicine, 2015 constituted $46 \%$.

Conclusions: The high inclination towards the use of atypical antipsychotics observed in our study correlates with the global changing trends in the treatment of schizophrenia. WHO prescribing indicators should be adhered to, to impart rational prescribing.

Keywords: Antipsychotics, Drug utilization, Olanzapine, WHO Prescribing indicators

\section{INTRODUCTION}

Psychiatric disorders have become the burden of illnesses in almost every country in the world due to its gigantic prevalence rate, acute onset, and consistent appearance. Almost all psychiatric disorder along with Schizophrenia are responsible for disability and premature death in the form of committing suicide, which is one of the leading causes of death worldwide with this disorder. ${ }^{1}$ Today about 450 million people are suffering from the psychiatric disorder, the majority of them belong to developing countries. ${ }^{2}$ Evidence collected from various global epidemiological researches indicate the prevalence rate of schizophrenia in the range of 1.4 to 4.6 per 1000 and the rate of incidence in the range of $0.16-0.42$ per 1000 populations. ${ }^{3}$ Out of top ten health conditions assigning for disability-adjusted life years (DALY), four are psychiatric disorders. $^{4}$ Recently, WHO estimates that the neuropsychiatric conditions attribute nearly one-third of all years lived with disability (YLDs) worldwide. ${ }^{2}$ According to various epidemiological studies the prevalence rate of psychiatric disorders fluctuates in between 9.5 to $370 / 1000$ populations in India. Data from studies conducted in India shows that about $20 \%$ of the population in the community is suffering from one or other psychiatric disorder. 
Psychosis is defined as massive deterioration in realitytesting ('not in contact' with reality) associated with notable personality disturbance, impairment in social, interpersonal and occupational functioning, loss of insight and presence of the characteristic symptoms, like delusions and hallucinations. ${ }^{6}$ Schizophrenia involves $1 \%$ of world's population. ${ }^{7-10}$ Schizophrenia cannot be cured completely but can be easily controlled with proper treatment. With appropriate treatment, affected person can lead to normal healthy life and can be unified with society. ${ }^{11}$ Symptoms may be clustered into three major groups-positive, negative and disorganized. ${ }^{12}$ It is noted that Schizophrenia typically originates in late adolescence or early adulthood. ${ }^{13}$

Psychopharmacology is a rapidly expanding field hence psychiatrists are frequently exposed to newly introduced drugs which are claimed and projected as the better alternatives to traditional psychiatric medicines. ${ }^{14}$ Although there are recommendations for antipsychotic monotherapy, still the prevalence of polypharmacy in the management of Schizophrenia is showing a steady increase. ${ }^{15}$ Polypharmacy can lead to needless expenses and also expose the patients to serious drug-related adverse effects. ${ }^{16,17}$

Now-a-days unnecessary drug consumption is a matter of concern in the global health system. The World Health Organization evaluates that more than half of all prescribed, distributed or sold drugs are not necessary for consumption and half of all patients suffer from medication errors even though they received appropriate medicines. ${ }^{18}$ Available literature shows lots of disparity in the prescription pattern of antipsychotics across different countries and even different regions in a same country. 5 Hence, it is essential to study the recent trends of antipsychotic prescription patterns to evaluate the prescribed treatment regimens against the standard guidelines. This may reinforce attitude to prevent the misuse of antipsychotics and to obtain rational and costeffective medical care. ${ }^{19}$ So, with this background in mind and also due to scarcity of data on the prescription pattern of antipsychotics from this part of North India, authors planned the present study in the Psychiatry out-patient Department of our medical college with the following objectives:

- To evaluate the current prescription pattern of antipsychotics.

- To analyse the prescriptions, based on WHO core prescribing indicators.

- To suggest modifications, if necessary, in prescribing patterns so as to make medical care rational and cost effective.

\section{METHODS}

A prospective, observational study was conducted by the Department of Pharmacology in collaboration with the Department of Psychiatry of Rohilkhand Medical College and Hospital. The study material comprised of the 310 eligible case records of patients attending Psychiatry OPD over a period of twelve (12) months (Nov 2016 to Oct 2017). Approval for the study was sought from the Institutional Ethics Committee (IEC) before the initiation of study and informed consent was taken from the patients.

\section{Sample size}

Patients of all age groups and either gender, attending Psychiatry OPD, diagnosed with any psychotic disorder on the basis of ICD-10 DCR criteria and those patients for whom an antipsychotic agent was prescribed either as main drug or concomitantly with other drug, comprised the sample size for the study. ${ }^{20}$ Patients whose diagnosis was not confirmed or who did not give voluntary informed consent were excluded from the study.

\section{Data collection technique and study tools}

Prescription was collected from the patients either by doing photocopy or by taking photograph or carbon copy. No follow up of the patient was done. A specially designed performa was used to collect the demographic and prescribing pattern data in the following format.

\section{Prescription pattern data}

- Types of psychotic disorders diagnosed

- Percentage of typical and atypical antipsychotics prescribed

- Percentage of antipsychotic monotherapy and polytherapy

- Most commonly prescribed typical and atypical antipsychotics

- Prescription was analysed using WHO Core prescribing indicators and compared with optimal value provided by $\mathrm{WHO}^{21,22}$

- Average number of drugs per prescription

- Average number of antipsychotics per prescription

- Percentage of drugs prescribed by generic name

- Percentage of encounters with an injection prescribed

- Percentage of drugs prescribed from National List of Essential Medicine 2015. ${ }^{23}$

\section{Statistical analysis}

The data was analysed using Microsoft Excel 2007 and results were displayed with the help of tables and graphs. Statistical Package for the Social Sciences (SPSS) for Windows Version 23.0 (SPSS Inc; Chicago, IL, USA) was used for Descriptive statistical analysis.

\section{RESULTS}

A total of 310 patients fulfilled the inclusion criteria and a male predominance was seen in the study population (male:female $=1.3: 1$ ). Majority of the patients belonged to the age group of 15-40 years of age, followed by a 
declining trend thereafter as depicted in Figure 1. 56\% of the patients were residents of urban area while $44 \%$ belonged to rural area as depicted in Figure 2.

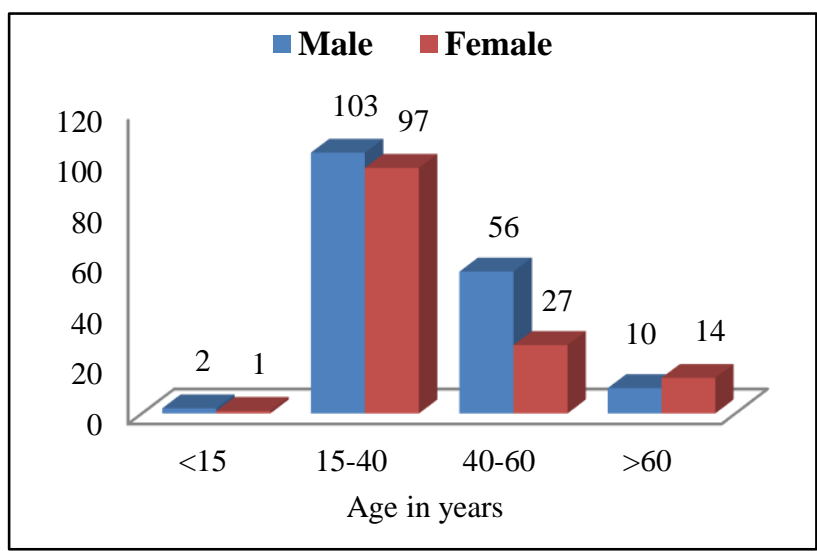

Figure 1: Age-wise distribution of both sexes.

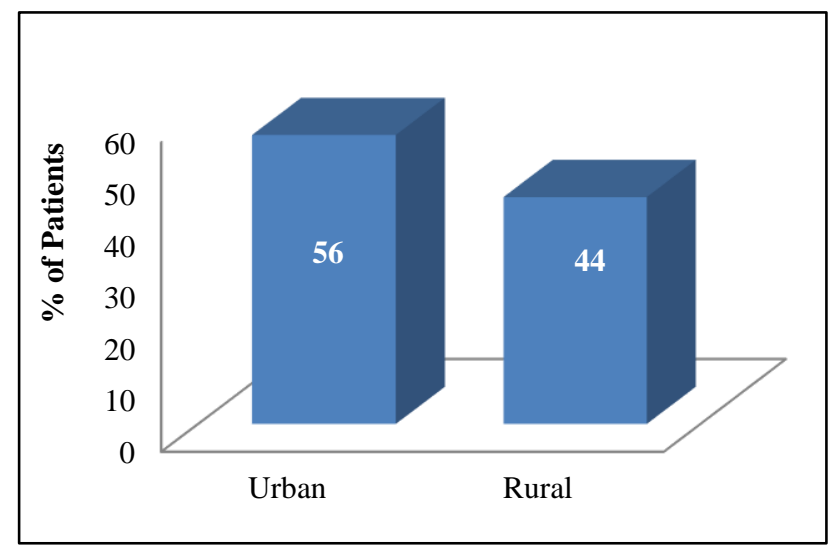

Figure 2: Distribution of patients according to habitat.

The most common psychotic disorder diagnosed was schizophrenia (44\%) followed by bipolar affective disorder $(29 \%)$ as seen in Figure 3.

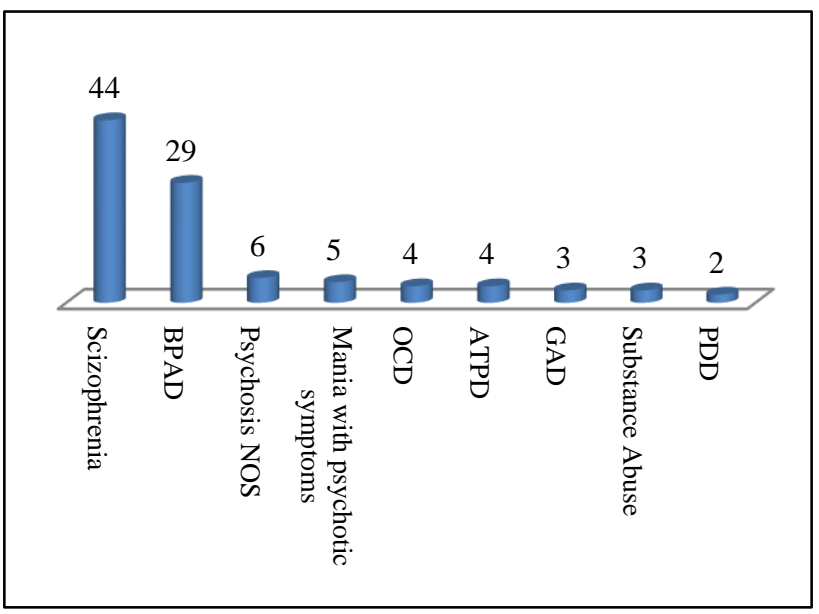

Figure 3: Percentage distribution of diseases in psychiatry OPD.
In the present study, polypharmacy was documented only in $24 \%$ of the prescriptions analysed while the rest $76 \%$ received Monotherapy (Figure 4). The prescribing trend showed a high inclination towards use of atypical antipsychotics.

\section{Monotherapy $\quad$ Polytherapy}

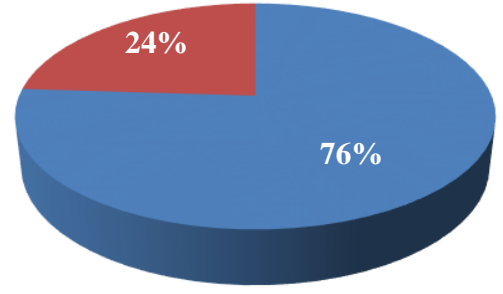

Figure 4: Monotherapy Vs polytherapy.

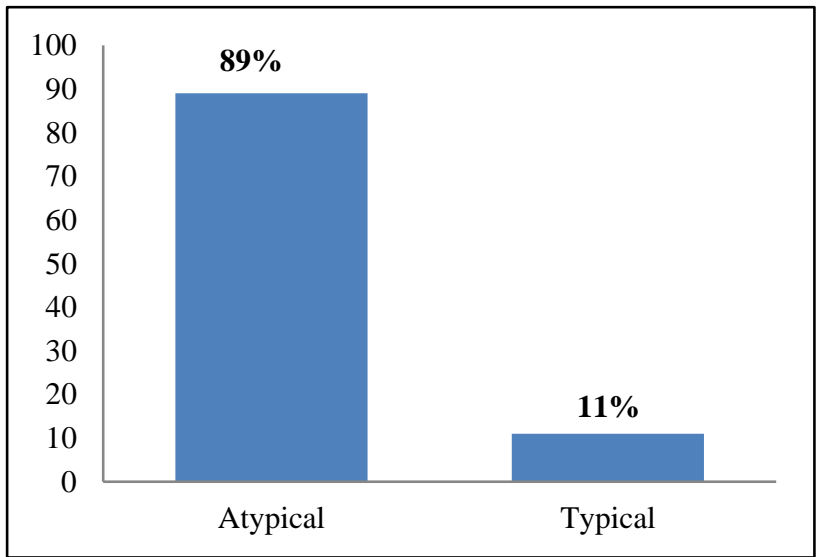

Figure 5: Percentage of the type of antipsychotic used.

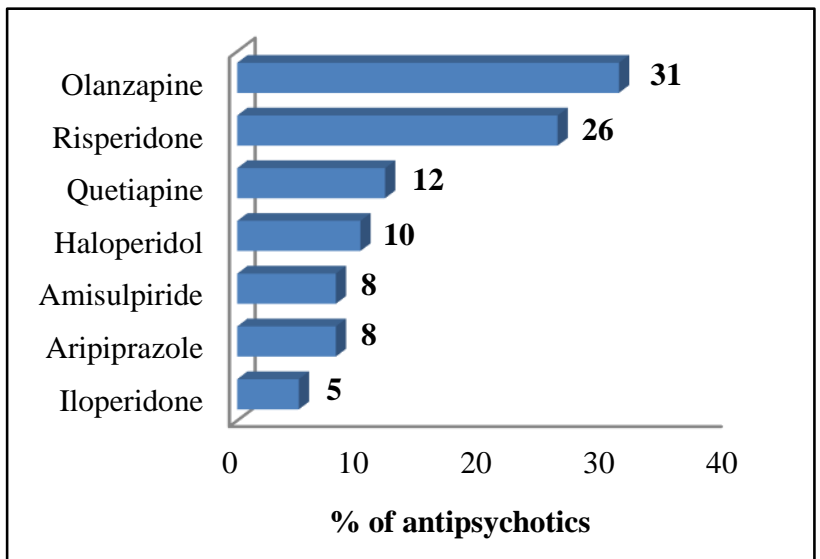

Figure 6: Prescribing pattern of antipsychotics in percentage.

Figure 5 reflects that $89 \%$ of atypical antipsychotics were prescribed as compared to $11 \%$ of typical antipsychotics. Figure 6 depicts the percentage utilization of drugs for the treatment of Schizophrenia and other psychotic disorders. 
The most commonly prescribed anti-psychotic drugs were olanzapine $(31 \%)$, followed by risperidone $(26 \%)$, quetiapine $(12 \%)$, haloperidol $(10 \%)$, amisulpiride $(8 \%)$, aripiprazole $(8 \%)$ and iloperidone $(5 \%)$.

Prescriptions were analysed according to the WHO Prescribing Indicators and it was observed that average number of drugs per prescription was 3.15 and average number of antipsychotics prescribed per prescription was 1.32. $24 \%$ of the drugs were prescribed by generic name. Percentage of drugs prescribed via injectable route was $5.2 \%$ only. Drugs prescribed from National list of Essential Medicine 2015 constituted 46\% (Table 1).

Table 1: Analysis of prescriptions according to WHO core prescribing indicators.

\begin{tabular}{|lll|}
\hline Drug use indicators & Outcome & $\begin{array}{l}\text { Optimal } \\
\text { value }\end{array}$ \\
\hline $\begin{array}{l}\text { Average number of drugs } \\
\text { prescribed per prescription }\end{array}$ & 3.15 & $1.6-1.8$ \\
\hline $\begin{array}{l}\text { Average number of } \\
\text { Antipsychotics prescribed per } \\
\text { prescription }\end{array}$ & 1.32 & $1.6-1.8$ \\
\hline $\begin{array}{l}\text { Percentage of the drugs } \\
\text { prescribed by generic name }\end{array}$ & $\begin{array}{l}98 / 410 \\
(24 \%)\end{array}$ & $100 \%$ \\
\hline $\begin{array}{l}\text { Percentage of injectable drugs } \\
\text { prescribed }\end{array}$ & $\begin{array}{l}16 / 310 \\
(5.2 \%)\end{array}$ & $13.4 \%-$ \\
\hline $\begin{array}{l}\text { Percentage of drugs prescribed } \\
\text { from National list of Essential }\end{array}$ & $\begin{array}{l}188 / 410 \\
(46 \%)\end{array}$ & $100 \%$ \\
\hline Medicine & & \\
\hline
\end{tabular}

Total number of prescriptions analysed 310; Total number of drugs prescribed 977; Total Number of antipsychotics prescribed 410 .

\section{DISCUSSION}

One of the burning issues in global health system is injudicious and irrational use of drugs. The burden of psychiatric disorders like Schizophrenia is also increasing enormously in the present scenario. Parallel to it the field of psychopharmacology is also growing exponentially with the introduction of new and improved drugs. But still, ironically, less than $30 \%$ of patients in the private sector and less than $40 \%$ of patients in the public sector are treated according to clinical guidelines in developing countries. ${ }^{24}$ To overcome such obstacles, World Health Organization and International Network for Rational Use of Drugs (INRUD) has recommended indicators of standard drug use which help us to detect the errors in prescription writing. ${ }^{19,25,26}$ Hence continuous Drug Utilization Studies of Anti-psychotic agents are needed to promote safe and effective therapy in the real-life situations.

In present study among 310 patients, a male: female ratio of 1.3:1 was seen. Present study finding of male preponderance was similar other studies done in Maharashtra by Sushma HK et al, and also by Thakare et al. ${ }^{27,28}$ However this finding is different from studies done in Indore by Atal S et al, and in Gujrat by Galani VJ et al. ${ }^{29,30}$

Majority of the patients were below 40 years of age $(65 \%)$ whereas only $35 \%$ of the patients were above 40 years of age. In addition to this, present study findings depicted that schizophrenia has an early age of onset, affecting males in their early twenties and females in their late twenties and early thirties. Similar findings were observed by Rode SB et al, and Ali A et al. ${ }^{31,32}$

In present study the most common psychotic disorder diagnosed was schizophrenia (44\%) followed by bipolar affective disorder $(29 \%)$ and so on. Other authors in the field like Rode SB et al, and George A et al, also documented similar prevalence of psychotic disorders. ${ }^{31,33}$ $24 \%$ of the prescriptions analysed by us showed polypharmacy while the rest $76 \%$ depicted monotherapy. A high inclination towards the use of atypical antipsychotics (89\%) was observed as compared to typical antipsychotics (11\%).

Atypical agents are endorsed as preferred agents because of their better efficacy, reduced chances of the extrapyramidal adverse effects, for improving negative symptoms, cognitive dysfunction and also for bringing response in patients resistant to conventional antipsychotics. Present study finding regarding favoured use of atypical anti-psychotics is in concordance with other authors in the field but in contrast to Sushma HK et al, who concluded that typical anti-psychotics were prescribed more as compared to atypical antipsychotics. ${ }^{27,34,35}$

Olanzapine (31\%) was the most frequently prescribed medication amongst anti-psychotics followed by risperidone $(26 \%)$, quetiapine $(12 \%)$, haloperidol $(10 \%)$, amisulpiride (8\%), aripiprazole (8\%) and iloperidone $(5 \%)$. These results of present study are in agreement with the findings of various other researchers like Siddiqui RA et al, found that olanzapine was the most commonly used antipsychotic drug in $51 \%$ of patients followed by risperidone in $23 \%$ and quetiapine in $13 \%$ of patients. ${ }^{36}$ Other less commonly used drugs were Aripiprazole in 6\%, Clozapine etc. Atal S et al, also reported similar findings, regarding the prescribing pattern of antipsychotics i.e. olanzapine $(28.08 \%)$, followed by risperidone $(25.84 \%)$ and haloperidol (23.03\%), among single agent antipsychotic drugs. ${ }^{29}$ The survey of the published literature of the recent past also reflects similar findings by Chakravarty $\mathrm{P}$ et al, Thakare $\mathrm{V}$ et al, and Rode SB et al. ${ }^{26,28,31}$

Prescription writing is a skill that reflects the competence of a physician and his attitude towards rational prescribing. Time and again systematic reviews have emphasized that prescribing errors are common and can affect from 4.2 to $82 \%$ of prescriptions. ${ }^{37}$

Prescription auditing is an educational tool to measure and monitor what we are prescribing against a reference 
standard. Hence regular auditing of prescriptions is extremely imperative in order to ensure high standard and best quality care to the patients. ${ }^{38}$ So, in this study we also conducted prescription auditing in Psychiatry OPD and compared the quality of prescriptions against the World Health Organization (WHO) recommended core prescribing indicators to investigate rational use of drugs. ${ }^{21}$

The prescription auditing results of present study showed that a total of 977 drugs were contained in 310 prescriptions. Out of which, 410 were antipsychotics. So, the average number of drugs per prescription was 3.15 and average number of antipsychotics per prescription was found to be 1.32. Other researchers in the field like Balaji $\mathrm{R}$ et al, and Kumar $\mathrm{S}$ et al, have also noted similar findings, whereas Rode SB et al, and George A et al, have reported lesser number of drugs per prescription i.e. 2.2 and 2.79 respectively. ${ }^{31,33,39,40}$ Average number of drugs per person is an important index of prescription audit. It is desirable to keep the mean number of drugs per prescription as low as possible, since higher figures are inclined to increase the risk of adverse effects, drug interactions and inflate the cost as well.

A very few drugs were prescribed by generic names in present study, being $24 \%$ only, while the rest $76 \%$ were prescribed by brand name. A similar trend of prescribing of drugs by brand names was observed by Rode SB et al, who noted only $30 \%$ of prescriptions with generic names. ${ }^{31}$ But George A et al, and Balaji R et al, reported a high use of generic drugs accounting to $98.15 \%$ and $76.34 \%$ respectively. ${ }^{33,39}$ Generic substitution should be recommended because these drugs are beneficial, provided adequate quality control is assured, and are also costeffective. $^{41}$

Most of the antipsychotics were prescribed by oral route except haloperidol which was given in injectable formulation $(5.2 \%)$ to control the acute episodes. Rode SB et al also reported use of only $9 \%$ of injectable medicines. $46 \%$ of the medicines were prescribed from NLEM 2015 in present study. ${ }^{23,31}$ Present study findings are in line with Balaji $\mathrm{R}$ et al, who found $50 \%$ use of medicines from NLEM 2015 and also with Patted UH et al, who found only $47.33 \%$ of patients received antipsychotics which were in the National list of essential medicines (NLEM) 2015. ${ }^{39,42}$ But Rode SB et al, and George A et al, have depicted a higher percentage (i.e. $81.36 \%$ and $96.77 \%$ ) use of drugs prescribed from essential drug list (WHO and Indian). ${ }^{31,33}$ This issue of under utilization of drugs from NLEM is of concern and can be redressed to some extent by prescriber education. The primary intention of NLEM is to promote rational use of medicines in terms of cost, safety and efficacy.

\section{CONCLUSION}

To conclude, present study has revealed that schizophrenia is the most common psychotic disease affecting males more than females. Patients suffering from psychotic illness are usually advised monotherapy. An increasing trend of prescribing atypical antipsychotics is noted, olanzapine being the most frequently prescribed drug followed by risperidone. As the percentage usage of generic drugs and incorporation of drugs from NLEM was low, so this issue needs to be refined and we recommend that the prescribing pattern should be improved by adhering to the WHO prescribing indicators for the betterment of public health.

\section{ACKNOWLEDGEMENTS}

The authors would like to acknowledge the support and cooperation of Dr. Santosh Kumar Consultant Psychiatry department for giving us a free access to analyse the prescriptions in his OPD.

\section{Funding: No funding sources}

Conflict of interest: None declared

Ethical approval: The study was approved by the Institutional Ethics Committee

\section{REFERENCES}

1. Reus VI. Mental disorders. In: Braunwald E, Fauci AS, Kasper DL, Hauser SL, Longo DL, Jameson JL and Loscalzo J, Eds. Harrison's principles of internal medicine. $17^{\text {th }}$ Edition. New York, NY: McGraw-Hill publication. 2008:2710-23.

2. World Health Organization: The World Health Report 2001: Mental health - new understanding, new hope Geneva: WHO; 2001. Available at: http://www.who.int/whr/2001/en/whr01_en.pdf

3. Jablensky A. Epidemiology of schizophrenia: the global burden of disease and disability. Eur Arch Psychiatry Clin Neurosci. 2000; 250(6):274-85.

4. Murthy RS. Mental health programme in the $11^{\text {th }}$ fiveyear plan. Indian J Med Res. 2007;125(6):707-12.

5. Karak S, Hati S, Sil S, Dalui SK, Kumar S. Polypharmacy dominated prescribing pattern of antipsychotic drugs in a tertiary care hospital. World J Pharmacy Pharmaceut Sci. 2016;5(6):1045-55.

6. Ahuja N. Other psychotic disorders. A short textbook of Psychiatry. $7^{\text {th }}$ Ed. Jaypee Brothers Medical Publishers (P) Ltd. 2011:83-8.

7. Insel TR. Rethinking schizophrenia. Nature. 2010;468(7321):187-93.

8. Purcell SM, Moran JL, Fromer M, Ruderfer D, Solovieff N, Roussos P et al. A polygenic burden of rare disruptive mutations in schizophrenia. Nature. 2014;506(7487):185-90.

9. Padmini Devi D, Amarjeeth R, Sushma M, Guido S. Prescription patterns of psychotropic drugs in hospitalized schizophrenic patients in a tertiary care hospital. Calicut Med J. 2007;5(4):e3.

10. Saha S, Chant D, Welham J, McGrath J. A systematic review of the prevalence of schizophrenia. PLoS Med. 2005;2(5):e141.

11. Sridhar S, Ravi K, Raju M, Thomas L. A pilot study on utilization pattern of antipsychotic drugs in 
schizophrenic patients from southern India. World J Pharma Pharmaceut Sci. 2017;6(7):1301-08.

12. Ahuja N. Schizophrenia. A short textbook of Psychiatry. $7^{\text {th }}$ Ed. Jaypee Brothers Medical Publishers (P) Ltd. 2011:54-68.

13. Jyothi NU, Pradeep P, Kumar MV, Sandeep K, Ramadasu P, Rao NR. Schizophrenia: psycho-social demographic profile and drug utilization study of antipsychotics at a government medical teaching hospital. World J Pharma Pharmaceut Sci. 2015;4(9):1036-45.

14. ESEMeD/MHEDEA 2000 investigators, Alonso J, Angermeyer MC, Bernert S, Bruffaerts R, Brugha TS, Bryson $\mathrm{H}$ et al. Sampling and methods of the European Study of the Epidemiology of Mental Disorders (ESEMeD) project. Acta Psychiatrica Scand. 2004;109:8-20.

15. Faries D, Ascher-Svanum H, Zhu B, Correll C, Kane J. Antipsychotic monotherapy and polypharmacy in the naturalistic treatment of schizophrenia with atypical antipsychotics. BMC Psychiatry. 2005;5(1):26.

16. Šagud M, Vuksan-Ćusa B, Živković M, Vlatković S, Kramarić M, Bradaš Z et al. Antipsychotics: to combine or not to combine? Psychiatria Danubina. 2013;25(3):306-10.

17. Kreyenbuhl JA, Valenstein M, McCarthy JF, Ganoczy D, Blow FC. Long-term antipsychotic polypharmacy in the VA health system: patient characteristics and treatment patterns. Psychiatric Services. 2007;58(4):489-95.

18. Brüggemann BR, Elgeti H, Ziegenbein M. Patterns of drug prescription in a psychiatric outpatient care unitthe issue of polypharmacy. Ger $\mathrm{J}$ Psychiatry. 2008;11:1-6.

19. Introduction to drug utilization research by World Health Organization. Geneva. 2003. Available at: http://apps.who.int/medicinedocs/pdf/s4876e/s4876e. pdf.

20. The ICD-10 Classification of Mental and Behavioural Disorders. Clinical descriptions and diagnostic guidelines. World Health Organization. Available at: http://www.who.int/classifications/icd/en/bluebook.p df.

21. WHO. How to investigate drug use in health facilities: selected drug use indicators - EDM research series No. 007. 1993. Available at: http://apps.who.int/medicinedocs/en/d/Js2289e.

22. Atif M, Sarwar MR, Azeem M, Umer D, Rauf A, Rasool A et al. Assessment of WHO/INRUD core drug use indicators in two tertiary care hospitals of Bahawalpur, Punjab, Pakistan. J Pharmaceut Policy Practice. 2016;9(1):27.

23. National list of Essential Medicine. 2015. Available at: http://cdsco.nic.in/WriteReadData/NLEM2015/NLEM,\%202015.pdf. Accessed on 01/07/2018.

24. Rational use of medicines. The Lancet. 2010; 375(9731): p 2052. Available at: https://www.thelancet.com/journals/lancet/article/PII S0140-6736(10)60944-0/fulltext Accessed on 01/07/2018.
25. Gupta N, Sharma D, Garg SK, Bhargava VK. Auditing of prescriptions to study utilization of antimicrobials in a tertiary hospital. Indian $\mathbf{J}$ Pharmacol. 1997;29(6):411-5.

26. Chakravarty P, Neog P, Dewan B. Prescribing pattern of antipsychotic drugs in the outpatient department of psychiatry in Silchar Medical College and Hospital, Assam. Open J Psychiatry Allied Sci. 2016;7(1):11-4.

27. Sushma HK, Jyothi CH, Somashekar HS, Avanthi E, Imran M, Raja B. Prescribing pattern of antipsychotic medications in patients with schizophrenia in a tertiary care hospital. Int $\mathbf{J}$ Basic Clin Pharmacol. 2017;4(1):134-8.

28. Thakare. V, Yadav. P. Observational study to evaluate prescription patterns in schizophrenia inpatient department of psychiatry unit. World J Pharmaceut Res. 2015;4(1):721-8.

29. Atal S, Atal S. Drug prescribing pattern and cost analysis of antipsychotics at a tertiary care hospital. Int J Pharmaceut Sci Res. 2016;7(6):2611-14.

30. Galani JV, Patel J, Patel K, Patel D. An epidemiological survey of patients suffering from schizophrenia in Gujarat. Mintage J Pharmaceut Med Sci. 2013:2(1);15-7.

31. Rode SB, Salankar HV, Verma PR, Sinha U, Ajagallay RK. Pharmacoepidemiological survey of schizophrenia in Central India. Int J Res Med Sci. 2017;2(3):1058-62.

32. Ali A. Disability in schizophrenia and its relationship with duration of illness and age of onset. International J Psychosocial Rehabilitation. 2009;14(2):37-41.

33. George A, Chaithra S, Thomas JE, James A, Siva Kumar T. Study on prescribing pattern in psychiatric disorders in a tertiary care hospital. Int $\mathbf{J}$ Innovative Pharmaceut Sci Res. 2016;4(6):641-7.

34. Banerjee I, Roy B, Sathian B, Banerjee I, Chakraborty PK, Saha A. Socio demographic profile and utilization pattern of antipsychotic drugs among schizophrenic inpatients: a cross sectional study from western region of Nepal. BMC Psychiatry. 2013;13(1):96.

35. Piparva KG, Parmar DM, Singh AP, Gajera MV, Trivedi HR. Drug utilization study of psychotropic drugs in outdoor patients in a teaching hospital. Indian J Psychol Med. 2011;33(1):54.

36. Siddiqui RA, Shende TR, Mahajan HM, Borkar A. Antipsychotic medication prescribing trends in a tertiary care hospital. Int $\mathbf{J}$ Basic Clin Pharmacol. 2017;5(4):1417-20.

37. Ross S, Bond C, Rothnie H, Thomas S, Macleod MJ. What is the scale of prescribing errors committed by junior doctors? a systematic review. $\mathrm{Br} \mathrm{J}$ Clin Pharmacol. 2009;67(6):629-40.

38. National Institute for Clinical Excellence (Great Britain). Principles for best practice in clinical audit. Radcliffe publishing;2002.

39. Balaji R, Sekkizhar M, Asok Kumar M, Nirmala P. An observational study of drug utilisation pattern and pharmacovigilance of antipsychotics. Int $\mathrm{J}$ Curr Pharmaceut Res. 2017;9(6):56-62. 
40. Kumar S, Chawla S, Bimba HV, Rana P, Dutta S, Kumar S. Analysis of Prescribing Pattern and Techniques of Switching Over of Antipsychotics in Outpatients of a Tertiary Care Hospital in Delhi: A Prospective, Observational Study. J Basic Clin Pharmacy. 2017;8(3):178-84.

41. Mathew P. Generic drugs: Review and experiences from South India. J Fam Med Primary Care. 2015;4(3):319-23.

42. Patted UH, Hema NG, Nagaraj AKM. Antipsychotics in schizophrenia: a retrospective study of drug utilization pattern in outpatient department of psychiatry at a tertiary care hospital. Int J Basic Clin Pharmacol. 2018;7(1):167-72.

Cite this article as: Shaifali I, Karmakar R, Chandra S, Kumar S. Drug utilization audit of antipsychotics using WHO methodology: recommendations for rational prescribing. Int J Basic Clin Pharmacol 2018;7:2021-7. 